\title{
Structural Elucidation of Lignins from Corncob Acid Hydrolysis Residue by Enzymatic Mild Acidolysis and Deep Eutectic Solvent Pretreatment
}

\author{
$\mathrm{Na} \mathrm{Li},{ }^{\mathrm{a}}$ Chao Cao, ${ }^{\mathrm{a}}$ Lupeng Shao, ${ }^{\mathrm{a}, *}$ Chao Wang, ${ }^{\mathrm{a}}$ Yu Liu, ${ }^{\mathrm{a}, *}$ Laizhi Sun,,${ }^{\mathrm{a}, \mathrm{b}}$ and \\ Lucian A. Lucia ${ }^{\text {a,c }}$
}

\begin{abstract}
Achieving mild and efficient extraction of high purity lignin from corncob acid hydrolysis residue is essential for efficient lignin application. In this study, enzymatic/mild acidolysis lignin (EMAL) and deep eutectic solvent (DES)-lignin were extracted from corncob acid hydrolysis residue. The structural features of the two lignin fractions were investigated by Fourier transform infrared spectroscopy (FTIR), thermogravimetric analysis (TGA), gel permeation chromatography (GPC), and ${ }^{31} \mathrm{P}$-nuclear magnetic resonance ( $\left.{ }^{31} \mathrm{P}-\mathrm{NMR}\right)$. The highest DES-lignin yield of 58.8 wt\% was achieved at $120{ }^{\circ} \mathrm{C}$ with a choline chloride-to-lactic acid (ChCl-to-Lac) molar ratio of 1:10 and a reaction time of $12 \mathrm{~h}$. The FTIR analysis indicated a higher amount of guaiacyl units in EMAL than DES-lignin. Furthermore, condensation and fragmentation occurred simultaneously under DES pretreatment, but the fragmentation reaction was dominant. The structural characteristics investigated will allow for more effective lignin usage.
\end{abstract}

Keywords: Corncob acid hydrolysis residue (CAHR); Lignin; Deep eutectic solvent (DES); Structural characterization

Contact information: a: State Key Laboratory of Biobased Material and Green Papermaking, Qilu University of Technology, Shandong Academy of Sciences, Jinan, Shandong 250353, China; b: Energy Research Institute of Shandong Academy of Sciences, Jinan, Shandong 250014, China; c: Department of Forest Biomaterials, North Carolina State University, Box 8005, Raleigh, NC 27695-8005, USA;

*Corresponding authors: shaolp@qlu.edu.cn; leoliuyu@163.com

\section{INTRODUCTION}

Alternative, sustainable fuel sources have received increased attention due to concerns of petroleum shortages and global warming (Ten and Vermerris 2013; You et al. 2016). Bio-ethanol produced from lignocellulose is attracting worldwide attention, as lignocellulose is the world's most abundant renewable resource (Zhang et al. 2012; Wang et al. 2018). Corncob, a common agricultural waste product, is the main feedstock for the production of bio-ethanol and xylose by acid hydrolysis. Acid hydrolysis residue (AHR) is a by-product in the hydrolysis process, and its availability has risen due to increased bioethanol and xylose production (Matsushita and Yasuda 2005). Lignin is one of the main components of AHR (Wang et al. 2014). Traditionally, AHR has been considered a waste material or low-value by-product and is usually burned for heat or power. The effective utilization of AHR is essential, as it can reduce production costs and prevent pollution caused by AHR discharge (Huang et al. 2012).

Lignin is the most abundant renewable resource composed of aromatic units in the plant world (Li et al. 2015). Lignin is mainly composed of three phenylpropane units, which are the $p$-hydroxyphenyl $(\mathrm{H})$ units, guaiacyl $(\mathrm{G})$ units, and syringyl $(\mathrm{S})$ units (Shao 
et al. 2018). The specific chemical structure of lignin makes it a sustainable alternative feedstock for the production of aromatic chemicals and performance products, such as phenol, BTX (benzene, toluene, and xylene) (Zakzeski et al. 2010), phenolic resins (Da Silva et al. 2013), polyurethanes (Pan and Saddler 2013), and carbon quantum dots (Wang et al. 2019). Despite its potential, the current industrial utilization of lignin is still limited due to its purity, yield, and complex chemical structure. In addition, the low solubility and functional group heterogeneity of lignin are major drawbacks to its use in polymer synthesis (Mbotchak et al. 2015). Due to the complicated linkages between lignin and other components in plants, the isolation of lignin from lignocellulosic biomass is challenging. Several processes for isolating lignin from lignocellulosic feedstocks have been developed. All such isolation methods have the same goals of obtaining high yield, high purity, and homogeneous lignin. In addition, lignins extracted by different methods exhibit different structural characteristics, which influence how the material can be used. A combination of enzymatic and mild acid hydrolysis can isolate high yield lignin (Wu and Argyropoulos 2003). Furthermore, enzymatic mild acidolysis lignin (EMAL) is more representative of the lignin typically present in milled lignin (Guerra et al. 2006). To find a better strategy to isolate lignin, deep eutectic solvent (DES) was investigated. Formed by mixing hydrogen bond donor (HBD) and hydrogen bond acceptor (HBA), DES has low volatility, nontoxicity, non-flammability, biocompatibility, and low cost (Zhang et al. 2016; Lynam et al. 2017; Liu et al. 2019). Tan et al. (2019) extracted $60 \mathrm{wt} \%$ of lignin from empty fruit bunches using acidic deep eutectic solvent. Additionally, lignin extracted by DES treatment has been reported to have high purity, high yield, and low molecular weight, which would be conducive to future utilization.

The comparable structural alterations of lignin from different integrated biorefineries have not been clearly determined due to the chemical technology and raw materials. Therefore, prior to utilization of lignin to chemicals and materials, comparative characterization of lignin obtained from different technologies is essential. In this study, EMAL and DES-lignin were obtained from corncob acid hydrolysis residue (CAHR). Two lignin fractions were characterized by Fourier transform infrared spectroscopy (FTIR), thermogravimetric analysis (TGA), gel permeation chromatography (GPC), and ${ }^{31} \mathrm{P}-$ nuclear magnetic resonance $\left({ }^{31} \mathrm{P}-\mathrm{NMR}\right)$. Comparative characterization of lignin from CAHR will facilitate faster development of chemicals and materials from lignin byproduct.

\section{EXPERIMENTAL}

\section{Materials}

The CAHR, obtained from Shandong Longlive Bio-Techbology Co., Ltd., Dezhou, China, was collected for feedstock. The corncob was treated hydrothermally to convert hemicellulose into oligosaccharides, producing a CAHR residue. The main compositions of CAHR were determined using the NREL Laboratory Analytical Procedure (Sluiter et al. 2008). The CAHR, which was dried prior to use, contained 25.85 wt $\%$ lignin, 62.34 wt $\%$ cellulose, and $6.12 \mathrm{wt} \%$ hemicellulose.

\section{Isolation of Lignins}

The EMAL was isolated from CAHR following the procedure described by $\mathrm{Wu}$ and Argyropoulos (2003). 
The DES-lignin was obtained by pretreatment of CAHR with prepared DES. The CAHR and DES were combined with a 1:30 ratio by weight. To remove extractives, CAHR was first extracted with mixed benzene and $95 \%$ ethanol for $8 \mathrm{~h}$. Then, DES was prepared by mixing choline chloride $(\mathrm{ChCl})$ and lactic acid $(\mathrm{Lac})$. The impact of the molar ratio of ChCl:Lac, reaction temperature, and reaction time were investigated. The DES pretreatment procedure is shown in Fig. 1. The yields of solid residue and extracted DESlignin were calculated using Eq. 1 and Eq. 2, respectively,

$$
\begin{aligned}
& \text { Yield of solid residue }(\mathrm{wt} \%)=W_{\mathrm{SR}} / W_{\mathrm{CAHR}} \times 100 \\
& \text { Yield of DES-lignin }(\mathrm{wt} \%)=W_{\mathrm{DES}-\text { lignin }} / W_{\text {lignin in CAHR }} \times 100
\end{aligned}
$$

where $W_{\text {SR }}(\mathrm{g})$ is the weight of solid residue, $W_{\text {CAHR }}(\mathrm{g})$ is the weight of CAHR, $W_{\text {DES-lignin }}$ $(\mathrm{g})$ is the weight of extracted DES-lignin, and $W_{\text {lignin in CAHR }}(\mathrm{g})$ is the weight of lignin in CAHR.

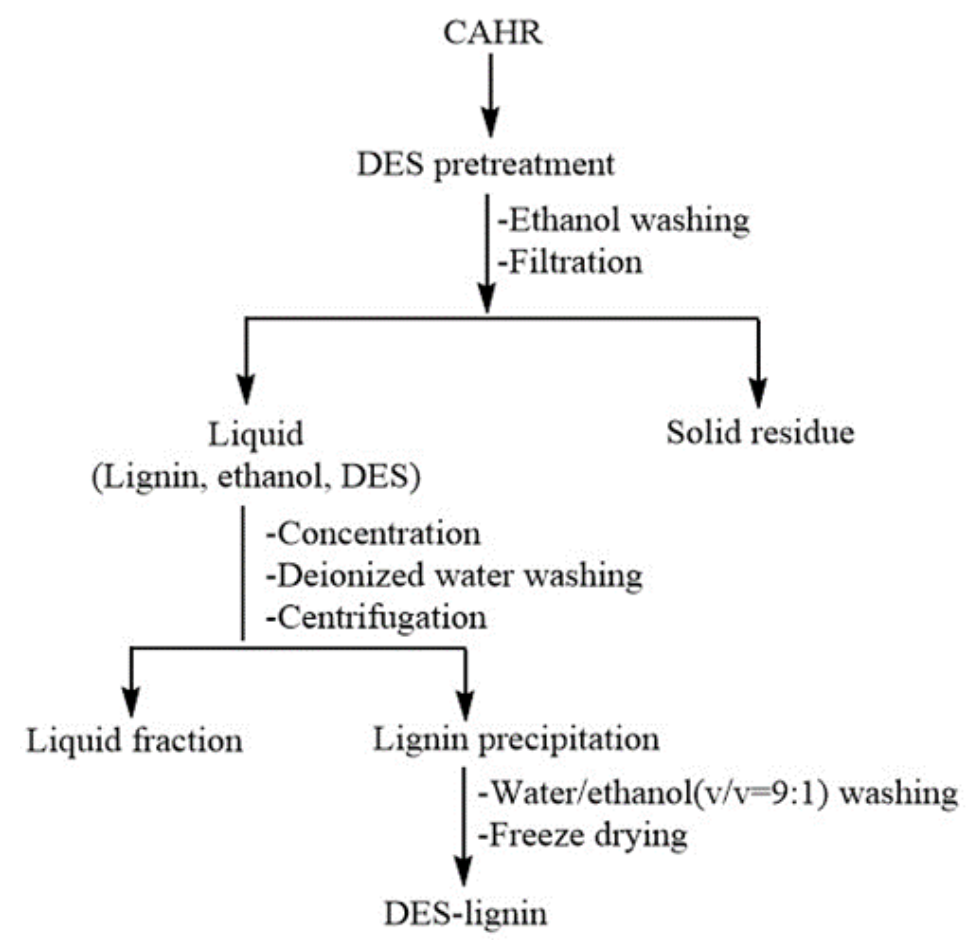

Fig. 1. The DES pretreatment procedure

\section{Methods}

FTIR analysis

Fourier-transform infrared spectra analysis of lignins was performed with a VERTEX70 instrument (Bruker, Karlsruhe, Germany) using a $\mathrm{KBr}$ pellet procedure. Lignins were scanned in the range of 4000 to $400 \mathrm{~cm}^{-1}$ with a resolution of $4 \mathrm{~cm}^{-1}$.

\section{Thermal stability}

Thermal stability of lignins were investigated on a STA449F3 simultaneous thermal analyzer (Netzsch, Selb, Germany). Approximately $10 \mathrm{mg}$ of lignin was placed in an alumina crucible and heated from ambient temperature to $800{ }^{\circ} \mathrm{C}$ with a heating rate of $10^{\circ} \mathrm{C} / \mathrm{min}$. High-purity nitrogen was used as the carrier gas with a flow rate of $40 \mathrm{~mL} / \mathrm{min}$. 


\section{Molecular weight determination}

The molecular weight distributions of the lignins were determined using an Alliance e2695 gel permeation chromatograph (Waters, Milford, MA, USA). Lignin was dissolved in tetrahydrofuran (THF), and $10 \mu \mathrm{L}$ of solution was injected into the column calibrated with polystyrene standards at a flow rate of $1 \mathrm{~mL} / \mathrm{min}$.

\section{${ }^{31} P$-NMR analysis}

Quantitative ${ }^{31} \mathrm{P}-\mathrm{NMR}$ spectra of lignins were acquired according to published procedures (Argyropoulos 1994; Granata and Argyropoulos 1995). Forty mg of lignin was completely dissolved in $650 \mu \mathrm{L}$ of pyridine and deuterated chloroform $(1.6: 1, \mathrm{v} / \mathrm{v})$. Next, $50 \mu \mathrm{L}$ of $\mathrm{N}$-hydroxy-5-norbornene-2,3-dicarboximide $(80 \mathrm{mg} / \mathrm{mL})$ was added as an internal standard, and $50 \mu \mathrm{L}$ of chromium(III) acetylacetonate $(11 \mathrm{mg} / \mathrm{mL})$ was added as a relaxation regent. Finally, $100 \mu \mathrm{L}$ of 2-chloro-4,4,5,5-tetramethyl-1,3,2-dioxaphospholate was added to the NMR tube for subsequent NMR analysis.

\section{RESULTS AND DISCUSSION}

\section{Yield Analysis}

The yield of EMAL, based on the initial lignin in CAHR, was $22.34 \mathrm{wt} \%$.

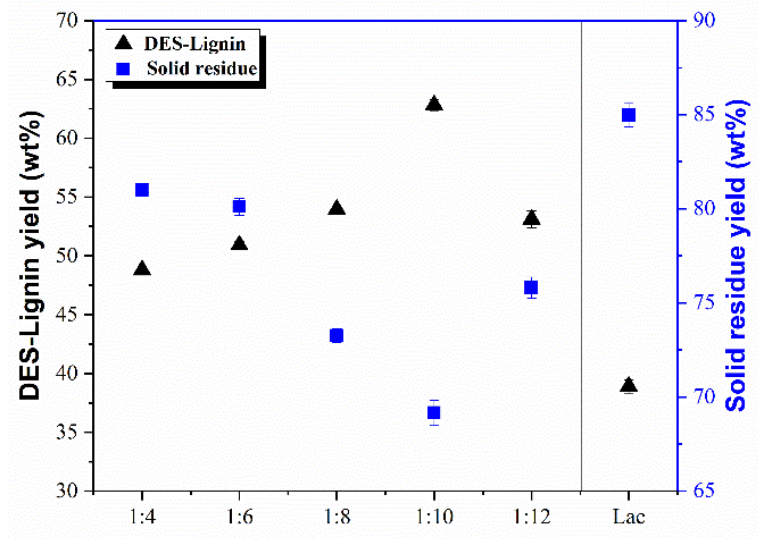

(a) $\mathrm{ChCl}$ to Lac (molar ratio)

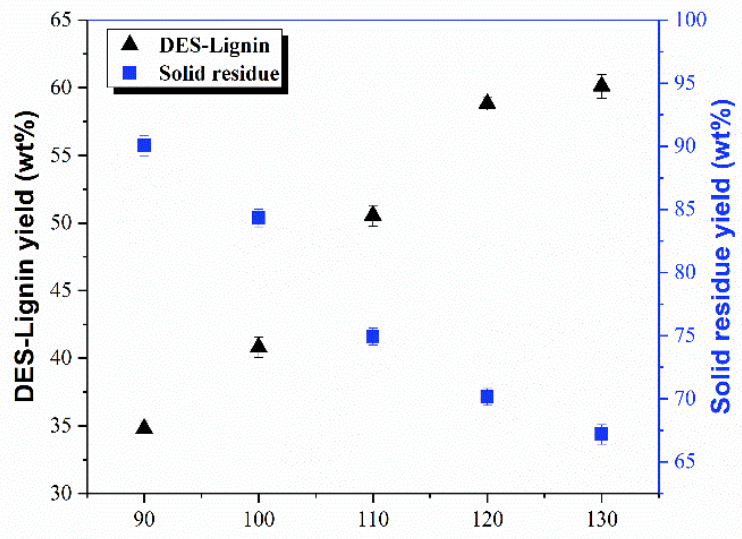

(b) Temperature ( $\left.{ }^{\circ} \mathrm{C}\right)$

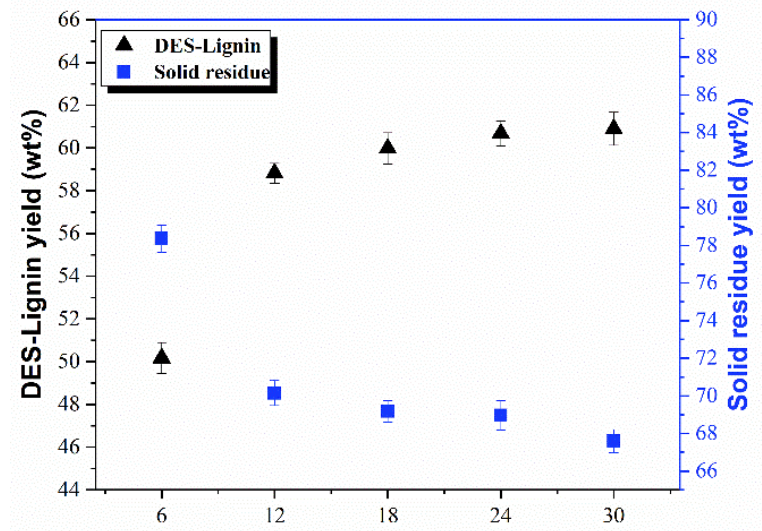

(c) Time (h)

Fig. 2. Effects of DES composition, temperature, and time on the extraction of DES-lignin. Condition: (a) Temperature, $120^{\circ} \mathrm{C}$; time, $12 \mathrm{~h}$ (b) ChCl-to-Lac molar ratio, 1:10; time, $12 \mathrm{~h}$ (c) $\mathrm{ChCl}$-to-Lac molar ratio, $1: 10$; temperature, $120^{\circ} \mathrm{C}$ 
The effects of DES composition, temperature, and time on the extraction of DESlignin are shown in Fig. 2. Five different molar ratios of ChCl-to-Lac (1:4, 1:6, 1:8, 1:10, and 1:12) were investigated. As the ChCl-to-Lac molar ratio increased from 1:4 to 1:10, the yield of DES-lignin gradually increased, and the solid residue yield decreased. The highest DES-lignin yield of $58.8 \mathrm{wt} \%$ with the lowest solid residue yield of $70.2 \mathrm{wt} \%$ was obtained with a ChCl-to-Lac molar ratio of 1:10. Increasing the lactic acid ratio decreased the DES-lignin yield to $53.1 \mathrm{wt} \%$ and increased solid residue yield. This might have been caused by an excess of lactic acid, which reduced the solubility of lignin in solvent. The result of the pure lactic acid pretreatment also supported this explanation. Figure $2 b$ shows the effect of temperature on the DES-lignin and solid residue yields. The yields of DESlignin and solid residue were highly temperature dependent. There were substantial yield changes in the temperature range of $90{ }^{\circ} \mathrm{C}$ to $120{ }^{\circ} \mathrm{C}$. The yield of DES-lignin increased from 34.8 to $58.8 \mathrm{wt} \%$ as temperature increased from $90{ }^{\circ} \mathrm{C}$ to $120^{\circ} \mathrm{C}$, and solid residue yield decreased from 90.1 to $70.2 \mathrm{wt} \%$. When the temperature was increased to $130{ }^{\circ} \mathrm{C}$, the yield of DES-lignin increased slowly. Therefore, $120{ }^{\circ} \mathrm{C}$ was the most appropriate temperature for DES pretreatment. Figure 2c shows the effect of time on DES pretreatment. The yield of DES-lignin increased as time increased from $6 \mathrm{~h}$ to $12 \mathrm{~h}$. With a pretreatment time of $12 \mathrm{~h}$, a $58.8 \mathrm{wt} \%$ yield of DES-lignin was obtained. Small variation in lignin yield was observed when the pretreatment time was greater than $12 \mathrm{~h}$. Thus, $12 \mathrm{~h}$ was the most suitable pretreatment time for obtaining high lignin yield. Based on the above findings, the optimum condition for ChCl-to-Lac pretreatment of CAHR was a ChCl-to-Lac molar ratio of $1: 10$, a temperature of $120^{\circ} \mathrm{C}$, and a time of $12 \mathrm{~h}$. These conditions resulted in a 58.82 $\mathrm{wt} \%$ DES-lignin yield.

\section{FTIR Analysis} CAHR.

Figure 3 shows the FTIR spectra of the EMAL and DES-lignin obtained from

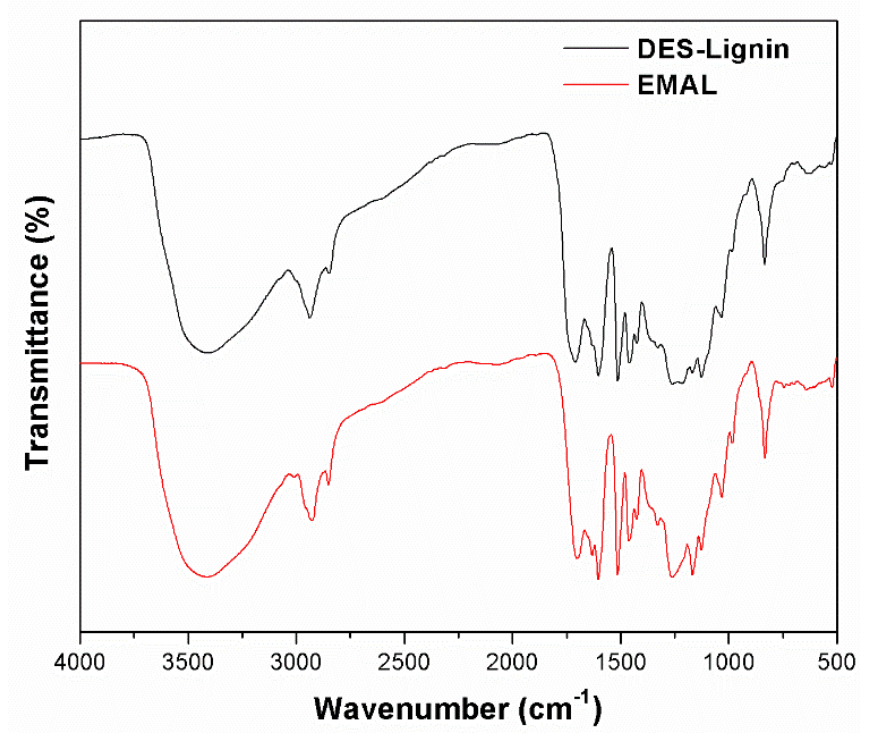

Fig. 3. The FTIR spectra of EMAL and DES-lignin

Table 1 lists the band assignments (Shao et al. 2017). The spectra of the EMAL and DES-lignin were similar except for the intensities of the absorption bands. A wide absorption band at $3420 \mathrm{~cm}^{-1}$ was assigned to the $\mathrm{O}-\mathrm{H}$ stretching vibration in aliphatic and 
aromatic $\mathrm{OH}$ groups, and the bands at 2930 and $2845 \mathrm{~cm}^{-1}$ represent the $\mathrm{C}-\mathrm{H}$ vibrations in the methyl and methylene groups. The band at $1710 \mathrm{~cm}^{-1}$ was attributed to unconjugated carbonyl stretching vibration in ketone or aldehyde groups. The spectrum of EMAL showed a stronger absorbance at $1630 \mathrm{~cm}^{-1}$, which was assigned to -COO- antisymmetric stretching of glucuronic acid or glucuronic acid carboxylate. This indicated that EMAL contained a high amount of glucuronic acid or glucuronic acid carboxylate. The bands at 1605,1510 , and $1425 \mathrm{~cm}^{-1}$ are attributed to aromatic skeletal vibrations (Wen et al. 2013). The bands at $1167 \mathrm{~cm}^{-1}$ indicated that the two lignin fractions were HGS-type lignins. The band at $1265 \mathrm{~cm}^{-1}$ (C-O stretching of guaiacyl ring) showed a stronger absorbance in EMAL, suggesting that it contained a higher amount of guaiacyl units than DES-lignin.

Table 1. Band Assignments for FTIR Spectrum of Lignin

\begin{tabular}{|c|c|}
\hline Wavenumber $\left(\mathbf{c m}^{-1}\right)$ & Band Assignment \\
\hline 3420 & O-H stretching vibration in hydroxyl groups \\
\hline 2930,2845 & C-H stretching vibration in methyl and methylene groups \\
\hline 1710 & $\mathrm{C}=\mathrm{O}$ stretching vibration in unconjugated ketone and carbonyl groups \\
\hline 1630 & COO- stretching vibration \\
\hline $1605,1510,1425$ & Aromatic skeletal vibrations \\
\hline 1265 & C-O stretching of guaiacyl ring \\
\hline 1167 & C-O-C symmetrical stretching vibration \\
\hline
\end{tabular}

\section{Thermal Stability Analysis}

The thermal properties of lignin have important implications for its utilization. The thermogravimetric (TG) and different thermogravimetric (DTG) curves of lignins are shown in Fig. 4. The thermal degradation behavior of these two lignin fractions was consistent. The thermal degradation process could be divided into three stages. The initial stage before $160{ }^{\circ} \mathrm{C}$ was mainly attributed to the release of water and some organic constituents. The second stage between $160{ }^{\circ} \mathrm{C}$ and $600{ }^{\circ} \mathrm{C}$ belonged to fast degradation stage in which lignin was converted into volatiles; this part would become bio-oil using condensation technology. The third stage from $600{ }^{\circ} \mathrm{C}$ to $800{ }^{\circ} \mathrm{C}$ belonged to a slow degradation stage, and char was the main product instead of bio-oil. In the fast degradation stage, the maximum rate of mass loss occurred at $374{ }^{\circ} \mathrm{C}$. Further, a $41.7 \mathrm{wt} \%$ char yield char was obtained from DES-lignin, whereas a $36.7 \mathrm{wt} \%$ char yield was obtained from EMAL, which could have been due to the difference in HGS units (Chen et al. 2015). This explanation is consistent with the FTIR results.
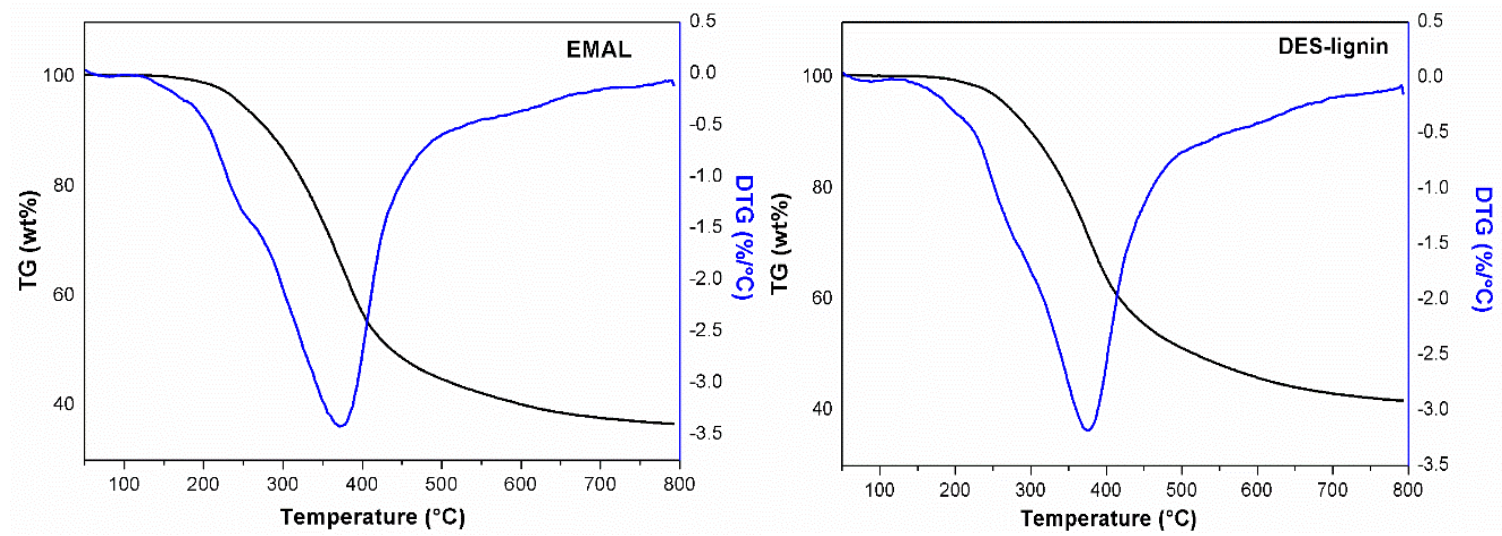

Fig. 4. TG and DTG curves of EMAL and DES-lignin 


\section{Molecular Weight Distribution}

The molecular weight distribution of lignin was obtained by gel permeation chromatography (You et al. 2015a). The number-average molecular weight $\left(M_{\mathrm{n}}\right)$, weightaverage molecular weight $\left(M_{\mathrm{w}}\right)$, and polydispersity (PDI, $\left.M_{\mathrm{w}} / M_{\mathrm{n}}\right)$ of EMAL and DESlignin are shown in Table 2. The weight-average molecular weight and number-average molecular weight of DES-lignin were 2601 and $1281 \mathrm{~g} / \mathrm{mol}$ respectively, which were substantially lower than 3384 and $1404 \mathrm{~g} / \mathrm{mol}$ of EMAL (Lyu et al. 2018). Lignin molecular weight is closely related to the amount of structural units. Therefore, the above result might have been caused by the breakage of lignin linkages during DES pretreatment, resulting in the formation of smaller fragments. It can be seen from Table 2 that the polydispersity value of DES-lignin was lower than that of EMAL, which indicated that lignin produced under DES pretreatment was relatively homogeneous. This was conducive to the more stable development of lignin into high value-added products. Furthermore, the condensation reaction would result in a heterogeneous lignin structure with higher molecular weight, whereas the fragmentation reaction would lead to a decrease in lignin molecular weight (You et al. 2015b). The results indicate that the fragmentation reaction was dominant over the condensation reaction in the DES pretreatment.

Table 2. Molecular Weight Distribution of Lignin Samples

\begin{tabular}{|c|c|c|c|}
\hline \multirow{2}{*}{ Lignin Sample } & \multicolumn{2}{|c|}{ Molecular Weight $(\mathbf{g} / \mathbf{m o l})$} & \multirow{2}{*}{ PDI $\left(\boldsymbol{M}_{\mathbf{w}} / \boldsymbol{M}_{\mathbf{n}}\right)$} \\
\cline { 2 - 3 } & $\boldsymbol{M}_{\mathbf{w}}$ & $\boldsymbol{M}_{\mathbf{n}}$ & 2.4101 \\
\hline EMAL & 3384 & 1404 & 2.0302 \\
\hline DES-Lignin & 2601 & 1281 & \\
\hline
\end{tabular}

\section{${ }^{31}$ P-NMR Analysis}

${ }^{31} \mathrm{P}-\mathrm{NMR}$ was used to differentiate and quantify the hydroxyl groups (phenolic, aliphatic, and carboxylic) in lignin ( $\mathrm{Pu}$ et al. 2011). The contents of different types of hydroxyl groups, which were determined by integration of the corresponding peaks with respect to the internal standard, are listed in Table 3 . The quantitative results showed that aliphatic hydroxyl dominated the hydroxyl groups. With respect to phenolic hydroxyl groups in EMAL, p-hydroxyphenyl phenolic hydroxyl was predominant, followed by guaiacyl and syringyl phenolic hydroxyl. The findings were similar to those in previous studies, indicating that the content of p-hydroxyphenyl phenolic hydroxyl in corncob or corn stalk lignin presented a high proportion among the phenolic hydroxyl groups (Liu et al. 2018; You et al. 2019). In contrast to the EMAL, the DES pretreatment led to a decrease in aliphatic hydroxyl content in DES-lignin. The content of aliphatic hydroxyl in DESlignin decreased to $1.17 \mathrm{mmol} / \mathrm{g}$. This reduction can be attributed to the dehydration reaction during the breakage of the $\beta-O-4$ linkage in the DES pretreatment process. The increase of syringyl phenolic hydroxyl content indicated that the syringyl unit in lignin underwent a greater extent of ether linkage cleavage during the DES pretreatment. This increase of $\mathrm{S}$ units could be attributed to the lack of association of lignin-carbohydrate complex in CAHR (Sun et al. 2015). In addition, an increase in condensed phenolic hydroxyl in DES-lignin occurred. Acidic conditions facilitate the recondensation of lignin (Gierer 1986). Consequently, lignin recondensation occurred in DES pretreatment. Meanwhile, the stable content of total phenolic hydroxyl meant that the lignin structure framework did not change. The $\mathrm{COOH}$ content increased slightly during DES pretreatment, indicating that an oxidation reaction occurred. 
Table 3. Quantification of Functional Groups in EMAL and DES-lignin by ${ }^{31} \mathrm{P}$ NMR

\begin{tabular}{|c|c|c|c|}
\hline $\begin{array}{c}\text { Chemical Shift } \\
\text { (ppm) }\end{array}$ & Assignment & \multicolumn{2}{|c|}{ Content (mmol/g) } \\
\cline { 3 - 4 } & EMAL & DES-lignin \\
\hline 134.4 to 137.0 & Carboxyl $(\mathrm{COOH})$ & 0.52 & 0.63 \\
\hline 137.0 to 138.4 & p-hydroxyphenyl phenolic hydroxyl $(\mathrm{H})$ & 1.03 & 0.81 \\
\hline 138.4 to 140.2 & Guaiacyl phenolic hydroxyl $(\mathrm{G})$ & 0.96 & 0.85 \\
\hline 142.4 to 143.6 & Syringyl phenolic hydroxyl (S) & 0.32 & 0.43 \\
\hline 140.2 to $142.4 /$ & Condensed phenolic hydroxyl & 0.35 & 0.52 \\
\hline 143.6 to 144.4 & Aliphatic hydroxyl & 1.71 & 1.17 \\
\hline 145.6 to 150.0 & Total phenolic hydroxyl & 2.66 & 2.61 \\
\hline- & Total hydroxyl & 4.37 & 3.90 \\
\hline- & & & \\
\hline
\end{tabular}

\section{CONCLUSIONS}

1. The enzymatic/mild acidolysis lignin (EMAL) and deep eutectic solvent (DES) lignin were extracted from corncob acid hydrolysis residue. A $58.8 \mathrm{wt} \%$ yield of DES-lignin was obtained under the optimum pretreatment conditions (ChCl-to-Lac molar ratio of $1: 10,120^{\circ} \mathrm{C}$, and $12 \mathrm{~h}$ ).

2. The FTIR spectra indicated that DES-lignin had a higher amount of guaiacyl units than the EMAL. In contrast with the EMAL, DES pretreatment led to decreases in the molecular weight and aliphatic hydroxyl content of the DES-lignin.

3. The GPC and ${ }^{31} \mathrm{P}-\mathrm{NMR}$ results indicated that both condensation and fragmentation reactions occurred under DES pretreatment, with the fragmentation reaction being the dominant reaction.

\section{ACKNOWLEDGMENTS}

The authors are grateful for the support of the National Key Research and Development Program of China (Grant No. 2017YFB0307905), the National Natural Science Foundation of China (Grant No. 31770626), the Shandong Provincial Natural Science Foundation (Grant No. ZR2019BC074), the Foundation of the State Key Laboratory of Biobased Material and Green Papermaking of the Qilu University of Technology and the Shandong Academy of Science (Grant No. ZZ20190103), and the Doctoral Cooperation Foundation of Qilu University of Technology and the Shandong Academy of Science (Grant No. 2018BSHZ0025). 


\section{REFERENCES CITED}

Argyropoulos, D. S. (1994). "Quantitative phosphorus-31 NMR analysis of lignins, a new tool for the lignin chemist," J. Wood Chem. Technol. 14(1), 45-63.

DOI: $10.1080 / 02773819408003085$

Chen, L., Wang, X., Yang, H., Lu, Q., Li, D., Yang, Q., and Chen, H. (2015). "Study on pyrolysis behaviors of non-woody lignins with TG-FTIR and Py-GC/MS," J. Anal. Appl. Pyrol. 113, 499-507. DOI: 10.1016/j.jaap.2015.03.018

Da Silva, C., Grelier, S., Pichavant, F., Frollini, E., and Castellan, A. (2013). "Adding value to lignins isolated from sugarcane bagasse and Miscanthus," Ind. Crop. Prod. 42, 87-95. DOI: 10.1016/j.indcrop.2012.04.040

Gierer, J. (1986). "Chemistry of delignification," Wood Sci. Technol. 20(1), 1-33. DOI: 10.1007/BF00350692

Granata, A., and Argyropoulos, D. S. (1995). "2-Chloro-4, 4, 5, 5-tetramethyl-1, 3, 2dioxaphospholane, a reagent for the accurate determination of the uncondensed and condensed phenolic moieties in lignins," J. Agr. Food Chem. 43(6), 1538-1544. DOI: 10.1021/jf00054a023

Guerra, A., Filpponen, I., Lucia, L. A., Saquing, C., Baumberger, S., and Argyropoulos, D. S. (2006). "Toward a better understanding of the lignin isolation process from wood," J. Agr. Food Chem. 54(16), 5939-5947. DOI: 10.1021/jf060722v

Huang, Y., Wei, Z., Qiu, Z., Yin, X., and Wu, C. (2012). "Study on structure and pyrolysis behavior of lignin derived from corncob acid hydrolysis residue," J. Anal. Appl. Pyrol. 93, 153-159. DOI: 10.1016/j.jaap.2011.10.011

Li, C., Zhao, X., Wang, A., Huber, G. W., and Zhang, T. (2015). "Catalytic transformation of lignin for the production of chemicals and fuels," Chem. Rev. 115(21), 11559-11624. DOI: 10.1021/acs.chemrev.5b00155

Liu, C., Wang, X., Lin, F., Zhang, H., and Xiao, R. (2018). "Structural elucidation of industrial bioethanol residual lignin from corn stalk: a potential source of vinyl phenolics," Fuel Process. Technol. 169, 50-57. DOI: 10.1016/j.fuproc.2017.09.008

Liu, Q., Zhao, X., Yu, D., Yu, H., Zhang, Y., Xue, Z., and Mu, T. (2019). "Novel deep eutectic solvents with different functional groups towards highly efficient dissolution of lignin," Green Chem. 21(19), 5291-5297. DOI: 10.1039/C9GC02306B

Lynam, J. G., Kumar, N., and Wong, M. J. (2017). "Deep eutectic solvents' ability to solubilize lignin, cellulose, and hemicellulose; thermal stability; and density," Bioresource Technol. 238, 684-689. DOI: 10.1016/j.biortech.2017.04.079

Lyu, G., Li, T., Ji, X., Yang, G., Liu, Y., Lucia, L., and Chen, J. (2018). "Characterization of lignin extracted from willow by deep eutectic solvent treatments," Polymers 10(8), 869. DOI: 10.3390/polym10080869

Matsushita, Y., and Yasuda, S. (2005). "Preparation and evaluation of lignosulfonates as a dispersant for gypsum paste from acid hydrolysis lignin," Bioresource Technol. 96(4), 465-470. DOI: 10.1016/j.biortech.2004.05.023

Mbotchak, L., Le Morvan, C., Duong, K. L., Rousseau, B., Tessier, M., and Fradet, A. (2015). "Purification, structural characterization, and modification of organosolv wheat straw lignin," J. Agr. Food Chem. 63(21), 5178-5188. DOI:

10.1021/acs.jafc.5b02071

Pan, X., and Saddler, J. N. (2013). "Effect of replacing polyol by organosolv and kraft lignin on the property and structure of rigid polyurethane foam," Biotechnol. Biofuels 6(1), 12. DOI: 10.1186/1754-6834-6-12 
Pu, Y., Cao, S., and Ragauskas, A. J. (2011). “Application of quantitative ${ }^{31} \mathrm{P}$ NMR in biomass lignin and biofuel precursors characterization," Energ. Environ. Sci. 4(9), 3154-3166. DOI: 10.1039/C1EE01201K

Shao, L., Zhang, Q., You, T., Zhang, X., and Xu, F. (2018). "Microwave-assisted efficient depolymerization of alkaline lignin in methanol/formic acid media," Bioresource Technol. 264, 238-243. DOI: 10.1016/j.biortech.2018.05.083

Shao, L., Zhang, X., Chen, F., and Xu, F. (2017). "Fast pyrolysis of kraft lignins fractionated by ultrafiltration," J. Anal. Appl. Pyrol. 128, 27-34. DOI: 10.1016/j.jaap.2017.11.003

Sluiter, A., Hames, B., Ruiz, R., Scarlata, C., Sluiter, J., Templeton, D., and Crocker, D. (2008). Determination of Structural Carbohydrates and Lignin in Biomass (NREL/TP-510-42618), National Renewable Energy Laboratory, Golden, CO, USA.

Sun, Q., Pu, Y., Meng, X., Wells, T., and Ragauskas, A. J. (2015). “Structural transformation of isolated poplar and switchgrass lignins during dilute acid treatment," ACS Sustain. Chem. Eng. 3, 2203-2210. DOI:

10.1021/acssuschemeng.5b00426

Tan, Y. T., Ngoh, G. C., and Chua, A. S. M. (2019). "Effect of functional groups in acid constituent of deep eutectic solvent for extraction of reactive lignin," Bioresource Technol. 281, 359-366. DOI: 10.1016/j.biortech.2019.02.010

Ten, E., and Vermerris, W. (2013). "Functionalized polymers from lignocellulosic biomass: State of the art," Polymers 5(2), 600-642. DOI: 10.3390/polym5020600

Wang, C., Lyu, G., Yang, G., Chen, J., and Jiang, W. (2014). "Characterization and hydrothermal conversion of lignin produced from corncob acid hydrolysis residue," BioResources 9(3), 4596-4607. DOI: 10.15376/biores.9.3.4596-4607

Wang, C., Zhang, Q., Chen, Y., Zhang, X., and Xu, F. (2018). "Highly efficient conversion of xylose residues to levulinic acid over $\mathrm{FeCl}_{3}$ catalyst in green salt solutions," ACS Sustain. Chem. Eng. 6(3), 3154-3161. DOI:

10.1021/acssuschemeng.7b03183

Wang, R., Xia, G., Zhong, W., Chen, L., Chen, L., Wang Y., Min, Y., and Li, K. (2019). "Direct transformation of lignin into fluorescence-switchable graphene quantum dots and their application in ultrasensitive profiling of a physiological oxidant," Green Chem. 21(12), 3343-3352. DOI: 10.1039/c9gc01012b

Wen, J. L., Xue, B. L., Xu, F., Sun, R. C., and Pinkert, A. (2013). "Unmasking the structural features and property of lignin from bamboo," Ind. Crop. Prod. 42, 332343. DOI: 10.1016/j.indcrop.2012.05.041

Wu, S., and Argyropoulos, D. (2003). "An improved method for isolating lignin in high yield and purity," J. Pulp Pap. Sci. 29, 235-240.

You, T., Shao, L., Wang, R., Zhang, L., and Xu, F. (2016). "Facile isothermal solid acid catalyzed ionic liquid pretreatments to enhance the combined sugars production from Arundo donax Linn," Biotechnol. Biofuels 9(1), 177. DOI: 10.1186/s13068-0160589-8

You, T., Zhang, L., Zhou, S., and Xu, F. (2015a). "Structural elucidation of lignincarbohydrate complex (LCC) preparations and lignin from Arundo donax Linn," Ind. Crop. Prod. 71, 65-74. DOI: 10.1016/j.indcrop.2015.03.070

You, T., Zhang, L., Guo, S., Shao, L., and Xu, F. (2015b). "Unraveling the structural modifications in lignin of Arundo donax Linn. during acid-enhanced ionic liquid pretreatment," J. Agr. Food Chem. 63(50), 10747-10756. DOI:

10.1021/acs.jafc.5b04831

Li et al. (2020). "Structure of acid hydrolysis lignins," BioResources 15(2), 4362-4372. 
You, T., Li, X., Wang, R., Zhang, X., and Xu, F. (2019). "Effects of synergistic fungal pretreatment on structure and thermal properties of lignin from corncob," Bioresource Technol. 272, 123-129. DOI: 10.1016/j.biortech.2018.09.145

Zakzeski, J., Bruijnincx, P. C., Jongerius, A. L., and Weckhuysen, B. M. (2010). "The catalytic valorization of lignin for the production of renewable chemicals," Chem. Rev. 110(6), 3552-3599. DOI: 10.1021/cr900354u

Zhang, H., Ding, F., Luo, C., Xiong, L., and Chen, X. (2012). "Liquefaction and characterization of acid hydrolysis residue of corncob in polyhydric alcohols," Ind. Crop. Prod. 39, 47-51. DOI: 10.1016/j.indcrop.2012.02.010

Zhang, C., Xia, S., and Ma, P. (2016). "Facile pretreatment of lignocellulosic biomass using deep eutectic solvents," Bioresource Technol. 219, 1-5. DOI: 10.1016/j.biortech.2016.07.026

Article submitted: January 12, 2020; Peer review completed: March 21, 2020; Revised version received and accepted: April 20, 2020; Published: April 23, 2020.

DOI: $10.15376 /$ biores.15.2.4362-4372 